\title{
The Quality of Life for People with Parkinson's Disease in Relation to Their Oral Health
}

\author{
Phablo Glewber Tôrres Bezerra1, Samuel Rodrigo de Andrade Veras' ${ }^{1}$, Camila Caroline da Silva1, \\ Renato Mariano da Silva', Deivison Edson Pereira da Silva', Eduardo Borges da Costa Leite'2, \\ Maria das Graças Wanderley de Sales Coriolano ${ }^{3}$, Carla Cabral dos Santos Accioly Lins ${ }^{3 *}$
}

${ }^{1}$ Federal University of Pernambuco, Recife, Brazil

${ }^{2}$ Department of Prosthodontics and Oral and Maxillofacial Surgery, Federal University of Pernambuco, Recife, Brazil

${ }^{3}$ Department of Anatomy, Federal University of Pernambuco, Recife, Brazil

Email: *cabralcarla1@hotmail.com

How to cite this paper: Bezerra, P.G.T., Veras, S.R. de A., da Silva, C.C., da Silva, R.M., da Silva, D.E.P., Leite, E.B. da C., Coriolano, M. das G.W. de S. and Lins, C.C. dos S.A. (2018) The Quality of Life for People with Parkinson's Disease in Relation to Their Oral Health. Open Journal of Stomatology, 8, 312-318.

https://doi.org/10.4236/ojst.2018.811029

Received: September 25, 2018

Accepted: November 4, 2018

Published: November 7, 2018

Copyright $\odot 2018$ by authors and Scientific Research Publishing Inc. This work is licensed under the Creative Commons Attribution International License (CC BY 4.0).

http://creativecommons.org/licenses/by/4.0/

\begin{abstract}
The present study aimed to evaluate the correlation between the oral health status and the quality of life for people with Parkinson's disease. The Decayed, Missing, Filled (DMFT) index and the quality of life questionnaire for people with Parkinson's disease (Parkinson's Disease Questionnaire-39) were used as evaluation instruments. Sixty-two people with a clinical diagnosis of Parkinson's disease between stages 1 and 3, age between 46 and 86 years, of both sexes, with an average time of disease evolution of 7 years, participated in the study. Data were evaluated using the Pearson's correlation test, and one-way ANOVA $(\mathrm{p}<0.05)$. The mean DMFT obtained was 23; there was no correlation between the DMFT values and the total score of the Parkinson's Disease Questionnaire-39 neither in its domains, nor between the DMFT and the stages of Parkinson's disease $(\mathrm{p}=0.61)$. We found that the oral health of parkinsonians is deficient due to the high number of missing teeth, but their perception of quality of life is favorable despite their motor limitations related to mobility, and activities of daily living.
\end{abstract}

\section{Keywords}

Parkinson's Disease, Quality of Life, DMFT Index

\section{Introduction}

Parkinson's disease (PD) has been studied since 1817 by the British physician James Parkinson as a progressive condition characterized by involuntary tremor with little muscular strength [1]. It is a chronic disease of the central nervous 
system, which presents itself as the main pathological finding degeneration in the compact portion of the substance nigra in the midbrain, which promotes nigrostriatal pathway dysfunction, with a decrease in dopamine production at dopaminergic receptors' level, located on the striated body [2] [3] [4]. Changes in motor control become noticeable in the patient characterized by: tremor, muscular rigidity and bradykinesia. In advanced clinical forms, postural alterations and balance and gait disorders usually occur [5] [6].

The treatment of the disease can be pharmacological, surgical and/or through non-pharmacological therapies (occupational therapy, physiotherapy, speech therapy, psychology, among others). In drug therapy, Levodopa is the most widely used substance and its prescription may be isolated or associated with dopaminergic agonists, anticholinergics, COMT (catechol-O-methyltransferase) inhibitors, and dopamine carboxylase inhibitors [7].

The effects of drugs of dopaminergic or anticholinesterase action affect the oral cavity promoting the reduction of saliva production, causing microflora imbalance, and increasing predisposition to periodontal diseases and caries. This fact, associated with physical limitation and function impairment, affects daily activities. Also, there is difficulty or even inability in the performance of their daily tasks. In this study, we will focus on the social and economic development of the population, which will limit their activity and social participation, often leading to social isolation, harming quality of life [8].

In PD, the quality of life can be assessed by a specific questionnaire: the Parkinson's Disease Questionnaire-39 (PDQ-39), which allows to inform with sufficient precision the negative impact of the disease on the quality of life of these people [9]. Few studies are found on the literature regarding the real impact of this disease on oral health; thus this study aimed to evaluate the existence of any association between the oral condition and quality of life for people with Parkinson's disease.

\section{Methodology}

\subsection{Ethical Considerations}

This work is linked to the research entitled: "Application of Mental Practice in Motor Learning of Brushing in Patients with Parkinson's”, registered in the Ethics Committee of the Federal University of Pernambuco/Brazil, obeying the Resolution of the National Health Council $n^{\circ} 66 / 12$, under the protocol $n^{\circ}$ 29242414.2.0000.5208, which is approved.

\subsection{Location of the Study}

The study was developed in the Pro-Parkinson Extension Project: Dentistry, located in Clinic C, in the Dentistry Course of the Federal University of Pernambuco/Brazil, located at the Department of Prosthodontics and Bucco-Facial Surgery. 


\subsection{Type and Study Population}

This is an analytical, quantitative, descriptive, cross-sectional study. These studies visualize the health status of the population at a given time, as snapshots of reality. It presents as advantages: to be adequate to test association hypotheses, their low cost, rapidness and ease of execution and analysis [10].

\subsection{Sample Calculation and Selection}

The sample calculation was based on a non-probabilistic sample (convenience), based on the number of patients who were attended at the Pro-Parkinson Extension Project: Dentistry's clinic between 2014 and 2016, by the following criteria: Inclusion Criteria-Parkinson's patients in stages 1 to 3 according to the Hoehn and Yahr [11] Scale who had at least sextant from the mouth with teeth; Exclusion criteria-Unsatisfactory communicative and cognitive level, verified through the Mini Mental State Exam.

\subsection{Data Collection}

The data in the medical records, collected from the information, was related to disease time since diagnose, the Hoehn and Yahr scale, the Decayed, Missing, Filled (DMFT) index and the data from the PDQ-39 quality of life questionnaire.

The Hoehn and Yahr Scale (HY) is an assessment of the disability of individuals with $\mathrm{PD}$, responsible for indicating their general state in a quick and practical way. The individuals classified between the stages 1 to 3 present mild to moderate disability, while those in stages 4 and 5 present severe disability [9] [11].

Teeth or surfaces that are decayed, missing, or filled (DMFT index)-This index represents the average number of decayed, lost and obturated permanent teeth in a population group, and is obtained from the sum of those. It is responsible for estimating the present and past experience of the dental caries attack on the permanent dentition [12].

PDQ-39 is a specific scale of quality of life assessment in PD patients, divided into eight dimensions: Mobility (10 items), Daily Life Activities (6 items), Emotional Well-Being (6 items), Stigma (4 Items), Social Support (3 items), Cognition (4 items), Communication ( 3 items) and Body Discomfort ( 3 items). These items can be answered with five different response options: "never"; "occasionally"; "sometimes"; "often"; "always" or "cannot do it at all". The scores range from: 0 (never) to 4 (always or cannot do it at all). The total score for each individual is calculated according to the following formula: $100 \times$ sum of the patient scores in the 39 questions $/ 4 \times 39$. The score of each dimension is obtained in the same way as the total score. The total score in the PDQ-39 ranges from: 0 (no problem) to 100 (maximum problem level) [9].

\subsection{Statistical Analysis}

The data was + compiled into Microsoft Excel spreadsheets and expressed as mild and standard deviation. Analysis of the correlation between DMFT and 
quality of life (PDQ-39) was performed using Pearson's correlation. To verify differences in DMFT between the stages of PD, one-way ANOVA was used. The statistical program used was BioEstat 5.3 considering $\mathrm{p}<0.05$.

\section{Results}

The sample consisted of 62 people with Parkinson's disease clinical diagnosis, being 39 men (62.9\%) and 23 women (37.1\%); in the stages HY1 = 20, HY2 $=29$ and HY3 $=13$ people. General characteristics of the sample studied are expressed in Table 1.

Regarding the dental health condition of the studied population, an average DMFT of $23( \pm 6)$ was observed, and a high degree of severity was noticed, due to the expressive number of losses; reaching almost 4 times the number of dental restorations. As the disease worsens, there is an increase in the number of missing teeth and a relatively small increase in the number of decayed teeth, with a decrease in the number of restored teeth (Figure 1).

The minimum and maximum values and the average score obtained in each dimension of the PDQ-39 are presented in Table 2. Numerically, individuals presented a worse perception of the QL in the dimensions "Body discomfort", "Mobility" and "Day Life Activities", and a better perception in the dimension "Social support". However, no correlation was observed between the DMFT values and the total PDQ-39 score in their domains (Figure 2), and no significant differences were noticed in the DMFT between the PD stages $(\mathrm{p}=0.61)$.

Table 1. Characteristics of the sample studied in relation to age, disease duration and disease severity.

\begin{tabular}{ccc}
\hline & Mean $( \pm)$ & Range \\
\hline HY & $2(1)$ & $1-3$ \\
Time of disease & $7(5)$ & $1-20$ \\
Age (years) & $62(10)$ & $46-86$ \\
\hline
\end{tabular}

$\mathrm{HY}=$ Scale of Hoehn \& Yahr.

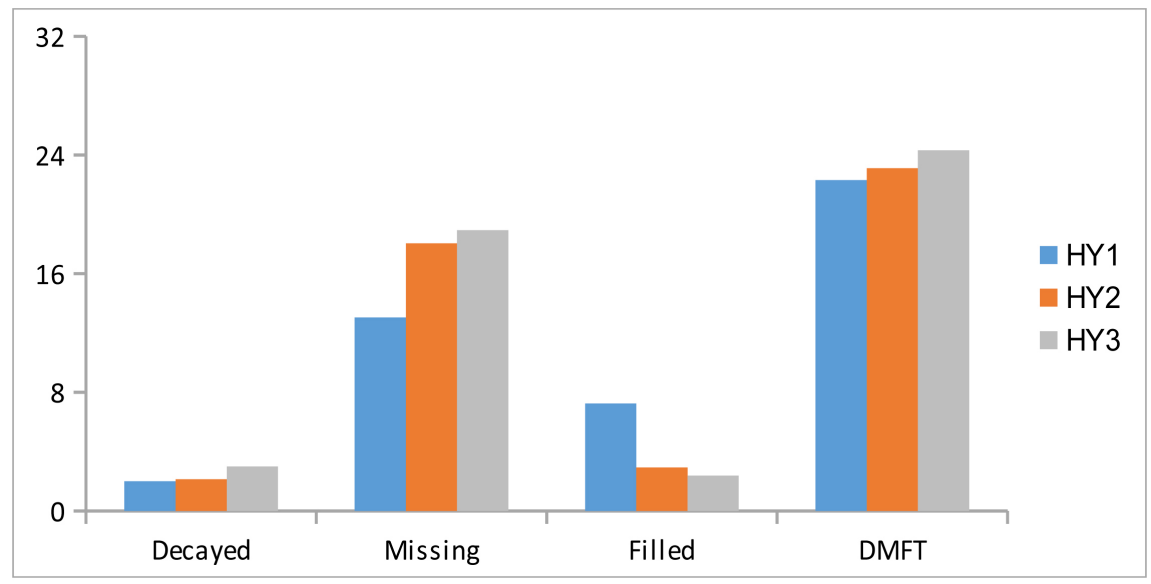

Figure 1. DMFT of people with Parkinson's disease per stage of the disease. 
Table 2. Descriptive statistics (mean, minimum and maximum values) of the total score and the score obtained in each dimension by means of the PDQ-39, in percentage.

\begin{tabular}{cccc}
\hline Dimensions & Mean $( \pm)$ & Minimum values (\%) & Maximum values (\%) \\
\hline Mobility & 39 & 0 & 95 \\
Day life activities & 36 & 0 & 100 \\
Emotional well-being & 34 & 0 & 100 \\
Stigma & 26 & 0 & 100 \\
Social support & 13 & 0 & 100 \\
Cognition & 26 & 0 & 100 \\
Communication & 27 & 0 & 100 \\
Body discomfort & 39 & 0 & 100 \\
PDQ-39 & 32 & 0 & 98.7 \\
\hline
\end{tabular}

PDQ-39 = Parkinson Disease Questionnaire-39.

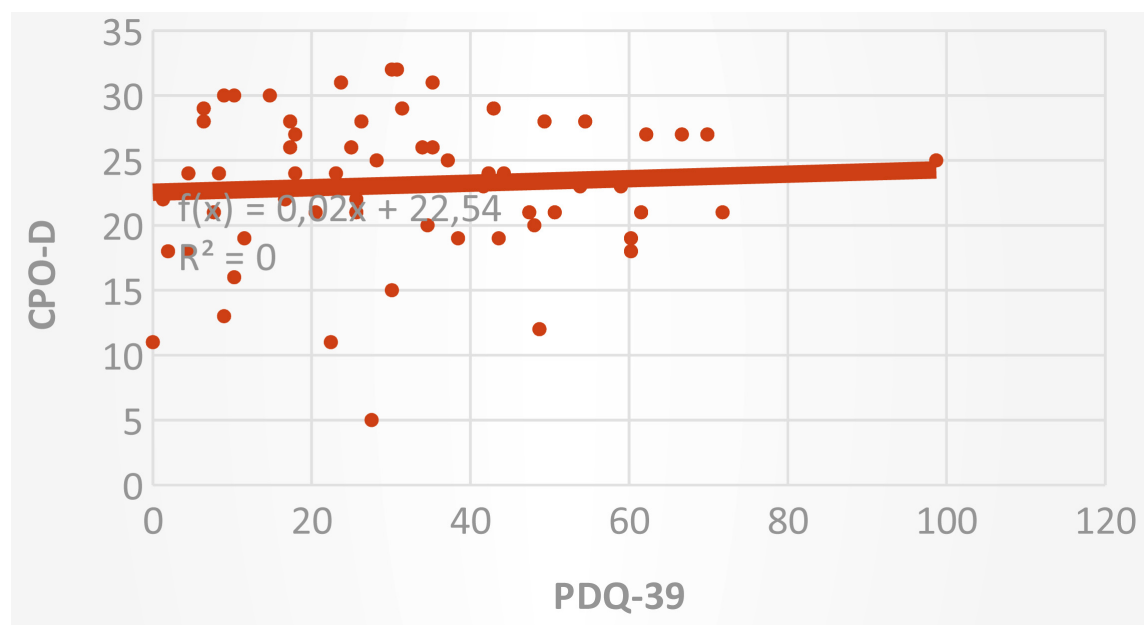

Figure 2. Correlation between DMFT and PDQ-39.

\section{Discussion}

The oral health condition found in the parkinsonians studied in this research was precarious, especially due to the high prevalence of edentulism, which is a serious problem of oral health that refers to a mutilating dental practice and the difficulty in accessing specialized dental services, contributing to other studies that evaluated the DMFT index [13] [14] [15]. With the worsening of the disease, it was also observed a greater loss of teeth. However, the scarcity of studies in the dental literature with this type of analysis limited the discussion of this association, making it difficult to identify a relationship between the disease and the condition of oral health in individuals with PD.

The concept of quality of life is multidimensional and reflects a subjective perspective of the personal satisfaction in relation to several aspects of his life, involving the person's family, functional, spiritual, social, occupational and financial issues [9]. In this context, oral health has a decisive role, because when it 
is compromised, it will affect the nutritional level, the physical and mental well-being, thus reducing pleasure and active social life [14].

Participants in this study had a low PDQ-39 score, which indicated a good perception of their quality of life, and no association was found with the DMFT index. This may have occurred because the sample was not in the more advanced stages of the disease. However, in the more advanced stages, symptoms such as: dementia, depression and speech difficulties interfere directly with the quality of life, and these factors intervene with the social function of the individual with PD [9] [16].

A recent German study of 100 parkinsonians sought to investigate access to dental health services and measure the impact of oral health on quality of life using the Oral Health Impact Profile (OHIP-14). The researchers observed that those Parkinsonians who had few symptoms of the disease had a better perception of their oral health, and that most (91.8\%) had their own dentist and visited them regularly [17].

Although there is a concern about the maintenance of the elderly's oral health status in the dental literature, there is a lack of content regarding the oral health care of people with PD [18]. Despite of the limitations in this research due to the lack of publications about oral health and quality of life for people with Parkinson's disease, another limitation is related to self-reporting because it involves social and psychological components. As well as PDQ-39 presents more specific assessment dimensions for general health signs and symptoms.

\section{Conclusion}

New studies are important in order to contribute to the improvement of oral health care and assistance of this group of people, seeking to establish programs that meet specific needs, both preventive and curative, so that the oral health conditions necessary to live with quality of life are maintained, despite the motor limitations imposed by the disease.

\section{Conflicts of Interest}

The authors declare no conflicts of interest regarding the publication of this paper.

\section{References}

[1] Steidl, E.M.S., Ziegler, J.R. and Ferreira, F.V. (2007) Parkinson's Disesase: Literature Revision. Disciplinarum Scientia, Ciências da Saúde, 8, 115-129.

[2] Armstrong, R.A. (2008) Visual Signs and Symptoms of Parkinson's Disease. Clinical and Experimental Optometry, 91, 129-138. https://doi.org/10.1111/j.1444-0938.2007.00211.x

[3] Prado, A.L.C., Puntel, G.O. and Souza, L.P. (2008) Analysis of Motor, Cognitive, and Depressive Manifestations in Parkinson's Disease Patients. Revista de Neurociêncas, 16, 10-15.

[4] Rosso, A.L.Z., Nicaretta, D.H. and Mattos, J.P. (2008) Anatomoclinical Correlation 
in Parkinson's Disease. Revista Brasileira de Neurolologia, 44, 41-47.

[5] Sanvito, W.L. (1997) Síndromes Neurológicas. 2nd Edition, Atheneu, São Paulo.

[6] Samii, A., Nutt, J.G. and Ransom, B.R. (2004) Parkinson's Disease. The Lancet, 363, 1783-1789. https://doi.org/10.1016/S0140-6736(04)16305-8

[7] Pinheiro, J.L.S. (2013) Doença de Parkinson e Outros Transtornos do Movimento [Parkinson's Disease and Othere Movement Disorders]. Oxford University Press, Oxford.

[8] Silva, F.S., Pabis, J.V.P.C., De Alencar, A.G., Da Silva, K.B. and Navarro-Peternella, F.M. (2010) Evolution of the Parkinson Disease and Impairment of Quality of Life. Revista de Neurociências, 18, 463-468.

[9] Lana, R.C, Álvares, L.M.R.S., Nasciutti-Prudente, C., Goulart, F.R.P., Teixeira-Salmela, L.F. and Cardoso, F.E. (2007) Perception of Quality of Life in Individuals with Parkinson's Disease Using the PDQ-39. Brazilian Journal of Physical Therapy, 11, 397-402.

[10] Almeida Filho, N. and Rouquayrol, M.Z. (2007) Elementos de metodologia epidemiológica. Epidemiologia e Saúde.

[11] Hoehn, M.M. and Yahr, M.D. (1967) Parkinsonism: Onset Progression and Mortality. Neurology, 17, 427-442. https://doi.org/10.1212/WNL.17.5.427

[12] Pinto, V.G. (2000) Saúde Bucal Coletiva, 4th Edition, Livraria Editora Santos, São Paulo.

[13] Gaião, L. and Almeida, M. (2004) Epidemiology of Tooth Decay, Periodontal Diseases, Use and Need of Prostheses in the Elderly Living in a Nursing Home in the City of Fortaleza, State of Ceará (Brazil). Revista Brasileira de Epidemiologia, 8, 316-323. https://doi.org/10.1590/S1415-790X2005000300013

[14] Sá, I.P.C., Almeida Júnior, L.R., Corvino, M.P.F. and Sá, S.P.C. (2012) Oral Health Conditions of the Elderly at the Lar Samaritano Long-Term-Care Facility in São Gonçalo-RJ. Ciência \& Saúde Coletiva, 17, 1259-1265. https://doi.org/10.1590/S1413-81232012000500019

[15] Freitas, Y.N., Lima, K.C. and Silva, D.A. (2016) Oral Health Status and Functional Capacity in the Elderly: A Longitudinal Population-Based Study. Revista Brasileira de Epidemiologia, 19, 670-674. https://doi.org/10.1590/1980-5497201600030016

[16] Camargo, A.C.R., Cópio, F.C.Q., Sousa, T.R.R. and Goulart, F. (2004) The Impact of Parkinson's Disease in Quality of Life: A Review of Literature. Brazilian Journal of Physical Therapy, 8, 267-272.

[17] Barbe, A.G., Bock, N., Derman, S.H.M., Felsch, M., Timmermann, L. and Noack, M.J. (2017) Self-Assessment of Oral Health, Dental Health Care and Oral Health-Related Quality of Life among Parkinson's Disease Patients. Gerodontology, 34, 135-143. https://doi.org/10.1111/ger.12237

[18] Lins, C.C.S.A., Lima, G.A., Maior, G.B.S., Wanderley, P.V.L., Roza, P.H.J. and Silva, D.E.P. (2015) Odontology Helping to Improve Health Quality of Oral Parkinson's Patients. Scientific-Clinical Odontology, 14, 627-630. 